\title{
Treatment effect of conversion therapy and its correlation with VEGF expression in unresectable rectal cancer with liver metastasis
}

\author{
GE HOU $^{1}$, RUI SONG ${ }^{1}$, JUN YANG $^{1}$, YANLING ZHANG $^{2}$, CHENHU XIAO $^{1}$, \\ CHENG WANG ${ }^{1}$, JINJIN YUAN ${ }^{1}$, TING CHAI ${ }^{1}$ and ZONGWEN LIU ${ }^{1}$ \\ ${ }^{1}$ Department of Tumor Radiotherapy, The Second Affiliated Hospital of Zhengzhou University, Zhengzhou, Henan 450014; \\ ${ }^{2}$ Department of Oncology, The Third People's Hospital of Zhengzhou University, Zhengzhou, Henan 450000, P.R. China
}

Received December 1, 2017; Accepted February 20, 2018

DOI: $10.3892 / \mathrm{ol} .2018 .8758$

\begin{abstract}
To investigate the therapeutic effect of conversion therapy and its correlation with vascular endothelial growth factor (VEGF) expression in unresectable rectal cancer with liver metastasis. A total of 116 cases of unresectable rectal cancer patients with liver metastasis were randomly divided into control and observation group, 58 cases in each group, all of these patients were treated by conversion therapy, patients in control were treated by FOLFOXIRI treatment program, and in observation group were treated by FOLFOXIRI program treatment and bevacizumab. Efficacy and adverse reactions were compared between the two groups, the levels of VEGF in portal vein and the expression of VEGF in cancer tissue were compared, after 5 years of follow-up, the prognosis of the two groups were observed. Objective efficiency and conversion rate of observation was significantly higher than the control group, survival rate of postoperative observation was significantly higher than that of control group $(\mathrm{P}>0.05)$. There was no significant difference in adverse reactions between the two groups $(\mathrm{P}>0.05)$. The positive rate of VEGF in portal vein blood and the expression of VEGF in the observation was significantly lower than that in the control group $(\mathrm{P}<0.05)$. The 5 -year survival rate of VEGF high expression was significantly lower than that of VEGF low expression group $(\mathrm{P}<0.05)$. FOLFOXIRI combined with bevacizumab in patients with unresectable hepatic metastasis of rectal cancer can provide higher conversion rate and hepatectomy opportunities, and reduce VEGF expression in patients with unresectable rectal cancer, which is closely related to VEGF expression, therefore it is beneficial to better local control and to improve long-term survival.
\end{abstract}

Correspondence to: Dr Zongwen Liu, Department of Tumor Radiotherapy, The Second Affiliated Hospital of Zhengzhou University, 2 Jingba Road, Zhengzhou, Henan 450014, P.R. China E-mail: youbang1025@163.com

Key words: rectal cancer, unresectable, conversion therapy, VEGF

\section{Introduction}

Rectal cancer is one of the most common malignant tumors of the digestive system in clinical practice, and its morbidity and mortality rates are among the top 5 in the world, showing increasing trends year by year (1). The incidence of colorectal cancer is a result of combined action of multiple factors. Its early symptoms are not obvious and easily ignored, leading to delayed diagnosis and treatment, so patients are usually in the advanced stage when diagnosed, more than half of whom will have distant liver metastasis (2). At present, rectal cancer has become one of the killers seriously threatening human health, and the preferred treatment method for colorectal cancer is radical surgery (3). Most patients are unable to receive surgery due to liver metastasis, which is also the leading cause of death. Patients with colorectal liver metastasis (CLMs) have a poor prognosis, and if there are no active and effective treatment measures, the 5-year survival rate is less than $10 \%$ (4). In previous years, with the application and promotion of multidisciplinary collaborative diagnosis and treatment modes, some unresectable CLMs can be resectable via conversion therapy, thus increasing the survival rate from 10 to $50 \%$, which is of great significance in increasing the surgical resection rate, extending the survival time and improving the prognosis of patients with CLMs (5). In the present study, different conversion therapies were performed for patients with CLMs, so as to investigate the therapeutic effects and its correlation with the vascular endothelial growth factor (VEGF) expression, providing a reference for the treatment of CLMs. It is now reported as follows.

\section{Materials and methods}

General materials. A total of 116 patients with advanced rectal cancer accompanied by liver metastasis treated in The Second Affiliated Hospital of Zhengzhou University (Zhengzhou, China) from October 2010 to October 2012 were selected as the objects of study. Inclusion criteria: i) Patients meeting the diagnostic criteria of colorectal cancer (6); ii) with liver metastasis; iii) with the survival time $>8$ weeks and unilateral lesions; and iv) who signed the informed consent. Exclusion 
Table I. General data of objects of study.

\begin{tabular}{|c|c|c|c|c|}
\hline \multirow[b]{2}{*}{ Items } & \multicolumn{2}{|c|}{ Groups } & \multirow[b]{2}{*}{$\mathrm{t} / \chi^{2}$} & \multirow[b]{2}{*}{ P-value } \\
\hline & Control $(\mathrm{n}=58)$ & Observation $(\mathrm{n}=58)$ & & \\
\hline Sex (male/female) & $26 / 32$ & $24 / 34$ & 0.035 & 0.851 \\
\hline Age (years) & $40-75$ & $40-78$ & & \\
\hline Average age (years) & $57.36 \pm 7.49$ & $57.85 \pm 7.58$ & 0.350 & 0.727 \\
\hline BMI $\left(\mathrm{kg} / \mathrm{m}^{2}\right)$ & $22.83 \pm 1.54$ & $22.56 \pm 1.27$ & 1.030 & 0.305 \\
\hline \multicolumn{5}{|l|}{ Primary tumor site, $\mathrm{n}(\%)$} \\
\hline Colon & $34(58.62)$ & $32(55.17)$ & 0.392 & 0.822 \\
\hline Rectum & $15(25.86)$ & $18(31.03)$ & & \\
\hline Junction between rectum and sigmoid colon & $9(15.52)$ & $8(13.79)$ & & \\
\hline Hepatic metastasis size $(\mathrm{cm})$ & $5.68 \pm 1.59$ & $5.85 \pm 1.68$ & 0.560 & 0.577 \\
\hline
\end{tabular}

BMI, body mass index.

criteria: i) Patients with mental diseases; and ii) who refused to cooperate or had very low compliance. Patients were randomly divided into control $(n=58)$ and observation group $(n=58)$. There were no statistically significant differences in general data between two groups of patients $(\mathrm{P}>0.05)$ (Table I).

\section{Methods}

Treatment. Patients in control group were treated with FOLFOXIRI. On the 1st day, $150-180 \mathrm{mg} / \mathrm{m}^{2}$ irinotecan (approval no. NMPN H20084572; Qilu Pharmaceutical Hainan Co., Ltd., Shandong, China) was intravenously injected for $90 \mathrm{~min}$, and $200 \mathrm{mg} / \mathrm{m}^{2}$ calcium folinate (approval no. NMPN H20000584; Jiangsu Hengrui Medicine Co., Ltd., Jiangsu, China) was also intravenously injected for $2 \mathrm{~h}$; then 400 mg/m² 5-fluorouracil (approval no. NMPN H31020593; Shanghai Xudong Haipu Pharmaceutical Co., Ltd., Shanghai, China) was intravenously injected, and then $2,400 \mathrm{mg} / \mathrm{m}^{2}$ 5-fluorouracil was pumped into peripheral vein for $46 \mathrm{~h}$. Patients in observation, based on the treatment in control group, received intravenous drip of $5 \mathrm{mg} / \mathrm{kg}$ bevacizumab (approval no. registration certificate no. S20120068; Roche Diagnostics, Indianapolis, IN, USA) for $\geq 1.5 \mathrm{~h}$ in the first, and for $\leq 1 \mathrm{~h}$ in the second time. Two groups of patients received the above treatment once every two weeks. After treatment, the curative effects on patients were dynamically evaluated, and the surgical resection could be scheduled when it was resectable. This study was approved by the Ethics Committee of The Second Affiliated Hospital of Zhengzhou University. Signed written informed consents were obtained from the patients and/or guardians.

Index detection. Fasting venous blood (3-5 ml) was drawn from patients in two groups, and serum was extracted to detect the VEGF concentration via enzyme-linked immunosorbent assay (ELISA). The relevant kits were provided by Reckitt Benckiser LLC (Parsippany, NJ, USA). According to the instructions of kit, the optical density value was read at a wavelength of $450 \mathrm{~nm}$ using a microplate reader from Jiangsu Potebio Co., Ltd., (Jiangsu, China), and the concentration of VEGF was calculated.
The expression of VEGF in tumor tissue samples was detected using the immunohistochemical method. The rabbit anti-human VEGF polyclonal antibody (1:800; cat. no. 2479) was provided by Cell Signaling Technology, Danvers, MA, USA. The paraffin-embedded tissues were cut into $4 \mu \mathrm{m}$-thick sections using a microtome (Leica, Germany), and baked in an incubator (Shanghai Medical Equipment Workshop) at $60^{\circ} \mathrm{C}$ overnight, followed by dewaxing via xylene. Then sections were placed into $95,85,80$ and $75 \%$ ethanol for $10 \mathrm{~min}$, respectively, soaked in distilled water for $5 \mathrm{~min}$, added with $50 \mu 13 \%$ hydrogen peroxide solution and incubated at $20^{\circ} \mathrm{C}$ for $10 \mathrm{~min}$. The activity of endogenous peroxidase was blocked; sections were washed with phosphate-buffered saline for 3 times, and added with $50 \mu \mathrm{l}$ primary antibody at $4^{\circ} \mathrm{C}$ overnight. After that, the goat anti-rabbit secondary polyclonal antibody (1:1,000; cat. no. 7074; Cell Signaling Technology), was added for incubation at $20^{\circ} \mathrm{C}$ for $10 \mathrm{~min}$, followed by color development using the reagents in DBA kit provided by Beijing Zhongshan Goldenbridge Biotechnology Co., Ltd. (Beijing, China), and observation under a microscope (Olympus, Tokyo, Japan). Distilled water was used to terminate the color development, followed by re-staining via hematoxylin for $2 \mathrm{~min}$ and sealing via neutral gum.

Evaluation criteria. The curative effect was evaluated based on the therapeutic evaluation criteria of solid tumors: Complete and partial remission, stable and progressive disease. Objective response rate $(\mathrm{ORR})=($ complete remission + partial remis sion)/total (7). The conversion rates of patients in two groups at 8,12 and 16 weeks after treatment were compared.

The VEGF concentration in portal venous blood was detected viaELISA. The expression of VEGFin tumor tissues was detected via immunohistochemistry, and the brown yellow-stained cells indicated the positive. Four high-power fields (x400) were randomly selected in each section, the percentage of positive cells was calculated, and the percentage point (PP) was scored: i) 0 point, no positive cells; ii) 1 , percentage of positive cells $<5 \%$; iii) $2,5 \%<$ percentage of positive cells $\leq 20 \%$; and iv) 3 , percentage of positive cells $>20 \%$. The staining intensity (SI) was also scored: i) 0 point, no staining; ii) 1 , pale yellow; iii) 2 , brown 
Table II. Comparisons of chemotherapeutic effects between two groups of patients n (\%).

\begin{tabular}{|c|c|c|c|c|c|}
\hline Groups & No. & Complete remission & Partial remission & Stable disease & Progressive disease \\
\hline Observation & 58 & $26(44.83)$ & $15(25.86)$ & $10(17.24)$ & $7(12.07)$ \\
\hline Control & 58 & $17(29.31)$ & $12(20.69)$ & $16(27.59)$ & $13(22.41)$ \\
\hline$\chi^{2}$ & & & & & 4.359 \\
\hline P-value & & & & & 0.037 \\
\hline
\end{tabular}

Table III. Comparisons of conversion rates between two groups of patients $\mathrm{n}(\%)$.

\begin{tabular}{lcccc}
\hline & & \multicolumn{3}{c}{ After treatment } \\
\cline { 3 - 5 } Groups & No. & 8 weeks & 12 weeks & 16 weeks \\
\hline Observation & 58 & $15(25.86)$ & $37(63.79)$ & $41(70.69)$ \\
Control & 58 & $11(18.97)$ & $19(32.76)$ & $29(50.00)$ \\
$\chi^{2}$ & & 0.446 & 9.977 & 4.359 \\
P-value & & 0.504 & 0.002 & 0.037 \\
\hline
\end{tabular}

Table IV. Comparisons of adverse reactions between two groups of patients $\mathrm{n}(\%)$.

\begin{tabular}{|c|c|c|c|c|c|}
\hline Groups & No. & Gastrointestinal reaction & Bone marrow suppression & Leucopenia & Liver dysfunction \\
\hline Observation & 58 & $2(3.45)$ & $1(1.72)$ & $1(1.72)$ & $1(1.72)$ \\
\hline Control & 58 & $4(6.90)$ & $3(5.17)$ & $3(5.17)$ & $4(6.90)$ \\
\hline$\chi^{2}$ & & 0.176 & 0.259 & 0.259 & 0.836 \\
\hline P-value & & 0.675 & 0.611 & 0.611 & 0.361 \\
\hline
\end{tabular}

yellow; and iv) 3, dark brown. The immune response score (IRS) was calculated according to the formula: IRS = PP x SI; IRS $>4$ points indicated the high expression, while IRS $\leq 4$ points indicated the low expression (8).

The incidence rates of recent adverse reactions, including gastrointestinal reaction, bone marrow suppression, leukopenia and liver dysfunction, were compared; Patients were followed-up for 5 years, and the survival time and rate of patients in different groups were recorded.

Statistical analysis. Data were processed using SPSS 19.0 software (SPSS, Inc., Chicago, IL, USA). Measurement data were presented as mean \pm standard deviation (SD), and t-test was used. Enumeration data were presented as rate, and Chi-square test was used. Survival analysis was performed via Kaplan-Meier analysis along with log-rank test. $\mathrm{P}<0.05$ was considered to indicate a statistically significant difference.

\section{Results}

Comparisons of chemotherapeutic effects between two groups of patients. ORR in observation $(79.69 \%)$ was significantly higher than that in control group $(50.00 \%)(\mathrm{P}<0.05)$ (Table II).

Comparisons of conversion rates between two groups of patients. There was no significant difference in conversion rate at 8 weeks after treatment between two groups $(\mathrm{P}>0.05)$. At 12 and 16 weeks after treatment, the conversion rates in observation were significantly higher than those in control group $(\mathrm{P}<0.05)$ (Table III).

Comparisons of adverse reactions between two groups of patients. The incidence rates of gastrointestinal reaction, bone marrow suppression, leukopenia and liver dysfunction had no significant differences between two groups of patients (P>0.05) (Table IV).

Comparison of VEGF between two groups of patients. After treatment, the VEGF concentration in portal venous blood and positive rate of VEGF expression in cancer tissue specimens in observation were obviously lower than those in control group $(\mathrm{P}<0.05)$ (Table V).

Comparisons of survival situations of patients in different groups. The average survival time in observation was longer than that in control group, and the postoperative 5-year survival rate was significantly higher than that in control group $(\mathrm{P}<0.05)$; the 5-year survival rate in high-expression VEGF was obviously lower than that in low-expression VEGF group, and the average survival time was obviously shortened compared with that in low-expression VEGF group $(\mathrm{P}<0.05)$ (Table VI and Figs. 1 and 2). 
Table V. VEGF concentration in portal venous blood and VEGF expression in cancer tissue specimens of patients.

\begin{tabular}{lccc}
\hline Groups & No. & $\begin{array}{c}\text { VEGF concentration } \\
\text { in portal venous blood }(\mu \mathrm{g} / \mathrm{l})\end{array}$ & $\begin{array}{c}\text { Positive rate } \\
\text { of VEGF expression } \mathrm{n}(\%)\end{array}$ \\
\hline Observation & 58 & $185.76 \pm 7.75$ & $27(46.55)$ \\
Control & 58 & $276.83 \pm 11.68$ & $47(81.03)$ \\
$\chi^{2} / \mathrm{t}$ & & 49.479 & 13.474 \\
P-value & & $<0.001$ & $<0.001$ \\
\hline
\end{tabular}

VEGF, vascular endothelial growth factor.

Table VI. Comparisons of 5-year follow-up status of patients in different groups.

\begin{tabular}{|c|c|c|c|c|}
\hline \multirow[b]{2}{*}{ Items } & \multicolumn{4}{|c|}{ Groups } \\
\hline & Observation $(\mathrm{n}=58)$ & Control $(n=58)$ & $\begin{array}{l}\text { High-expression } \\
\text { VEGF }(\mathrm{n}=56)\end{array}$ & $\begin{array}{l}\text { Low-expression } \\
\text { VEGF }(\mathrm{n}=60)\end{array}$ \\
\hline 5-year survival rate n (\%) & $28(48.28)$ & $12(20.69)$ & $11(18.97)$ & $29(48.33)$ \\
\hline$\chi^{2}$ & & 8.598 & & 9.322 \\
\hline $\mathrm{P}$-value & & 0.003 & & 0.002 \\
\hline Average survival time (month) & $49.83 \pm 7.68$ & $40.16 \pm 6.85$ & $38.86 \pm 7.52$ & $49.93 \pm 7.75$ \\
\hline t-test & & 7.156 & & 7.807 \\
\hline P-value & & $<0.001$ & & $<0.001$ \\
\hline
\end{tabular}

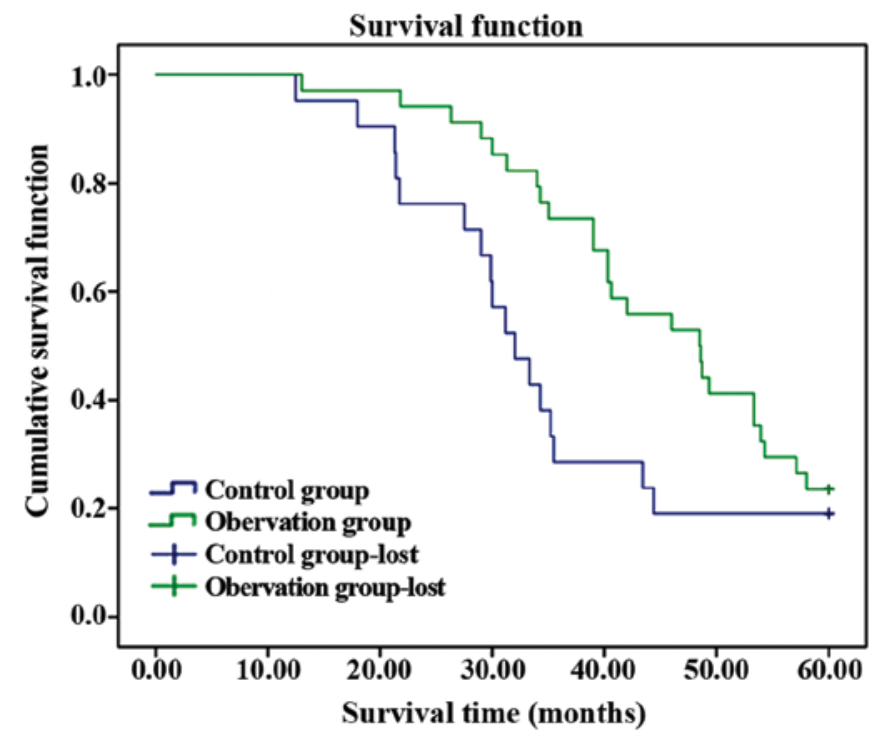

Figure 1. Survival curves of patients in observation and control groups.

\section{Discussion}

With the changes in people's living habits and aggravation of environmental pollution, the incidence rate of rectal cancer has continued to rise. Colorectal cancer is caused by various factors, including lifestyle (obesity, smoking, drinking, drugs and psychosocial factors), diet (high-protein diet, high-fat diet and trace elements), gastrointestinal diseases (ulcerative colitis, Helicobacter pylori infection and Crohn's disease)

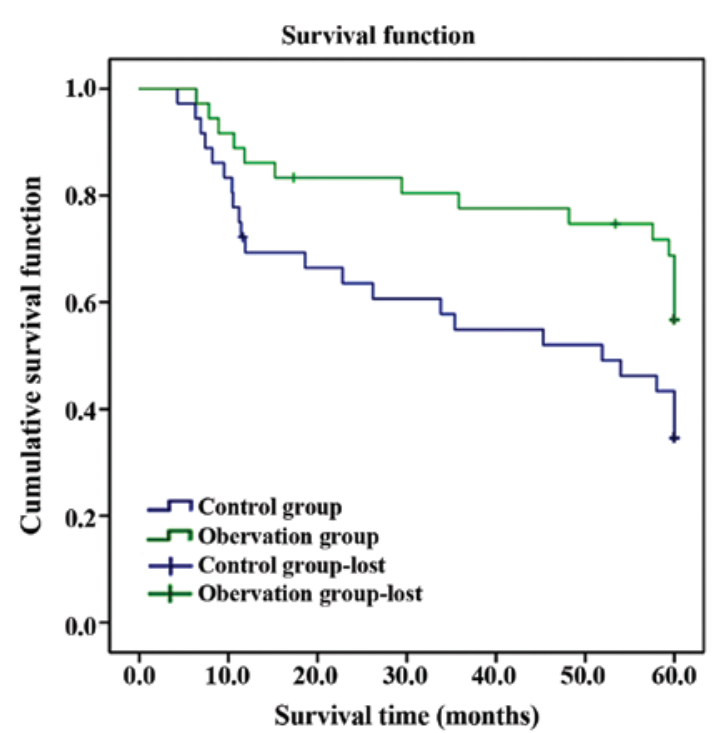

Figure 2. Survival curves of patients with different VEGF expressions VEGF, vascular endothelial growth factor.

and genetic factors; in particular, the fat intake was positively correlated with the incidence of rectal cancer $(9,10)$. The molecular pathways of occurrence and development of rectal cancer can be divided into two types; chromosome and microsatellite instability (MSI). The main pathogenesis of rectal cancer is chromosomal deletion, and MSI is another important pathogenesis of colorectal cancer, among which MSI pathway is mainly caused by the defects and changes in DNA mismatch repair (MMR) system (11). MMR gene is one 
of important members in DNA repair system. The incidence of many malignant tumors, especially colorectal cancer, is closely related to the changes in MMR gene (12).

Colorectal cancer, especially early rectal cancer, can be cured only by surgical treatment, but most patients have been in the late stage when diagnosed, and those with advanced CLMs cannot receive surgical treatment (13). Conversion chemotherapy refers to a treatment strategy that the unresectable cancer initially becomes resectable after chemotherapy, and the surgical indications are expanded through conversion therapy, thus curing the patients (14). The results of this study showed that ORR and conversion rate in observation were significantly higher than those in control group, and the postoperative survival rate in observation was also significantly higher than that in control group $(\mathrm{P}<0.05)$. This is because the conversion therapy and efficacy evaluation of CLMs patients can make the cancer in some patients become resectable, and timely surgical treatment is performed before the disappearance of lesions, thus effectively prolonging the survival time of patients with CLMs. FOLFOXIRI program includes three drugs: 5-fluorouracil, irinotecan and leucovorin, among which irinotecan is a kind of semi-synthetic camptothecin derivative, as well as an effective drug in the treatment of rectal cancer, and it can also inhibit DNA replication (15). Leucovorin and 5-fluorouracil are drugs for the treatment of advanced rectal cancer, and they can be combined with definite effects (16). Bevacizumab is a kind of recombinant humanized, human-mouse chimeric anti-VEGF monoclonal antibody drug. The combined application of the above drugs based on FOLFOXIRI program can obtain more definite effects, resulting in a higher remission rate and more obvious conversion effect (17).

VEGF is a specific angiogenic factor with the highest and strongest activity, which is a member in the platelet-derived growth factor family that can stimulate vascular endothelial cells and promote the division and proliferation, eventually promoting the neovascularization (18). VEGF is highly expressed in many tumor tissues and is closely related to the pathological grading of malignant tumors (19). Venous blood returns to the liver mainly via the portal vein system and then enters the venous system. The detection of VEGF concentration in venous blood of patients with CLMs can effectively evaluate the condition of disease (20). The results of this study showed that after treatment, the VEGF concentration in portal venous blood and the positive rate of VEGF expression in cancer tissue specimens in observation were significantly lower than those in control group $(\mathrm{P}<0.05)$, and the incidence rates of gastrointestinal reaction, bone marrow suppression, leucopenia and liver dysfunction had no significant differences between two groups of patients $(\mathrm{P}>0.05)$. This is because FOLFOXIRI program combined with bevacizumab can directly block the activation of VEGF and regulate or inhibit the vasculature of tumors, thus preventing the neovascularization of tumor. At the same time, bevacizumab can inhibit tumor differentiation factors, control the neovascularization from the source, result in cell hypoxia and apoptosis, and prevent the process of pseudo-vascular normalization. Neovascularization is an important basic condition for the growth and migration of tumor cells. Bevacizumab can effectively lower the pressure in the tumor stroma and reduce the exudation by decreasing the tumor vascular bed and changing its permeability, and more effectively release the 5-fluorouracil, irinotecan and leucovorin into tumor cells, thereby inhibiting the VEGF overexpression, reducing the neovascularization and enhancing the anticancer effect, without increasing the damage to normal cells and incidence rate of adverse reactions. FOLFOXIRI program combined with bevacizumab conversion therapy leaves a large space for the conversion therapy and increases the resectability. Patients were followed-up for 5 years, and it was found that the 5-year survival rate in high-expression VEGF was significantly lower than that in low-expression VEGF group, and the average survival time was significantly shortened compared with that in low-expression VEGF group.

In the conversion therapy, it is believed that the over-conversion should be avoided without pursuing the remission rate excessively. When the cancer is resectable, surgery should be performed as soon as possible before the disappearance of metastasis, and chemotherapy should be withdrawn at this time. If not, the metastasis may continue to grow and become unresectable once again, missing the window of surgery. If metastasis disappears, liver segment resection or hepatic lobectomy is still needed in the original lesions.

In conclusion, the FOLFOXIRI program combined with bevacizumab target therapy for CLMs patients can improve the effective rate of conversion therapy, and its therapeutic effect is closely related to the expression of VEGF. After conversion therapy, performing active surgical resection can effectively improve the survival time of patients, which has a very great clinical significance.

\section{Acknowledgements}

Not applicable.

\section{Funding}

No funding was received.

\section{Availability of data and materials}

All data generated or analyzed during this study are included in this published article.

\section{Authors' contributions}

GH, RS and JY designed the study. YZ, CX and CW collected the data, JW and TC analysed the data, GH and ZL prepared the manuscript. ZL performed ELISA. All authors read and approved the final manuscript.

\section{Ethics approval and consent to participate}

This study was approved by the Ethics Committee of The Second Affiliated Hospital of Zhengzhou University (Zhengzhou, China). Signed written informed consents were obtained from the patients and/or guardians.

\section{Consent for publication}

Not applicable. 


\section{Competing interests}

The authors declare that they have no competing interests.

\section{References}

1. Brenner H, Kloor M and Pox CP: Colorectal cancer. Lancet 383 1490-1502, 2014

2. Kahi CJ, Boland CR, Dominitz JA, Giardiello FM, Johnson DA, Kaltenbach T, Lieberman D, Levin TR, Robertson DJ and Rex DK: Colonoscopy surveillance after colorectal cancer resection: Recommendations of the US multi-society task force on colorectal cancer. Gastrointest Endosc 83: 489-98.e10, 2016.

3. Page AJ, Weiss MJ and Pawlik TM: Surgical management of noncolorectal cancer liver metastases. Cancer 120: 3111-3121, 2014.

4. Sotirchos VS, Petrovic LM, Gönen M, Klimstra DS, Do RK, Petre EN, Garcia AR, Barlas A, Erinjeri JP, Brown KT, et al: Colorectal cancer liver metastases: Biopsy of the ablation zone and margins can be used to predict oncologic outcome. Radiology 280: 949-959, 2016.

5. Fulong W and Pan Z: Operation time of colorectal liver metastasis and choice of operation after convertible therapy. Chin J Pract Surg 33: 656-659, 2013.

6. Corley DA,JensenCD,Marks AR,Zhao WK,LeeJK, DoubeniCA, Zauber AG, de Boer J, Fireman BH, Schottinger JE, et al: Adenoma detection rate and risk of colorectal cancer and death. N Engl J Med 370: 1298-1306, 2014

7. Li J, Hao D, Wang L, Wang H, Wang Y, Zhao Z, Li P, Deng C and Di LJ: Epigenetic targeting drugs potentiate chemotherapeutic effects in solid tumor therapy. Sci Rep 7: 4035, 2017.

8. Jagadish N, Parashar D, Gupta N, Agarwal S, Sharma A, Fatima R, Suri V, Kumar R, Gupta A, Lohiya NK, et al: A novel cancer testis antigen target A-kinase anchor protein (AKAP4) for the early diagnosis and immunotherapy of colon cancer. OncoImmunology 5: e1078965, 2016.

9. Dunet V, Halkic N, Prior JO, Anaye A, Meuli RA, Sempoux C, Denys A and Schmidt S: Detection and viability of colorectal liver metastases after neoadjuvant chemotherapy: A multiparametric PET/CT-MRI study. Clin Nucl Med 42: 258-263, 2017.

10. Truant S, Séquier C, Leteurtre E, Boleslawski E, Elamrani M, Huet G, Duhamel A, Hebbar M and Pruvot FR: Tumour biology of colorectal liver metastasis is a more important factor in survival than surgical margin clearance in the era of modern chemotherapy regimens. HPB 17: 176-184, 2015.

11. Venderbosch S, Nagtegaal ID, Maughan TS, Smith CG, Cheadle JP, Fisher D, Kaplan R, Quirke P, Seymour MT, Richman SD, et al: Mismatch repair status and BRAF mutation status in metastatic colorectal cancer patients: A pooled analysis of the CAIRO, CAIRO2, COIN, and FOCUS studies. Clin Cancer Res 20: 5322-5330, 2014.
12. Alexandrescu S, Diaconescu A and Popescu I. Surg options synchronous liver metastases colorectal cancer. Transl. J. Med. Res 22: 10-21, 2017.

13. Wagner M, Ronot M, Doblas S, Giraudeau C, Van Beers B, Belghiti J, Paradis V and Vilgrain V: Assessment of the residual tumour of colorectal liver metastases after chemotherapy: Diffusion-weighted MR magnetic resonance imaging in the peripheral and entire tumour. Eur Radiol 26: 206-215, 2016.

14. Bregendahl S, Emmertsen KJ, Fassov J, Krogh K, Zhao J, Gregersen $\mathrm{H}$ and Laurberg S: Neorectal hyposensitivity after neoadjuvant therapy for rectal cancer. Radiother Oncol 108: 331-336, 2013.

15. Glimelius B, Ristamäki R, Kjaer M, Pfeiffer P, Skovsgaard T, Tveit KM, Linné T, Frödin JE, Boussard B, Oulid-Aïssa D, et al: Irinotecan combined with bolus 5 -fluorouracil and folinic acid Nordic schedule as first-line therapy in advanced colorectal cancer. Ann Oncol 13: 1868-1873, 2002.

16. Van Cutsem E, Lenz HJ, Köhne CH, Heinemann V, Tejpar S, Melezínek I, Beier F, Stroh C, Rougier P, van Krieken JH, et al: Fluorouracil, leucovorin, and irinotecan plus cetuximab treatment and RAS mutations in colorectal cancer. J Clin Oncol 33: 692-700, 2015.

17. Heinemann V, von Weikersthal LF, Decker T, Kiani A, Vehling-Kaiser U, Al-Batran SE, Heintges T, Lerchenmüller C, Kahl C, Seipelt G, et al: FOLFIRI plus cetuximab versus FOLFIRI plus bevacizumab as first-line treatment for patients with metastatic colorectal cancer (FIRE-3): A randomised, open-label, phase 3 trial. Lancet Oncol 15: 1065-1075, 2014.

18. Hamnvik OPR, Choueiri TK, Turchin A, McKay RR, Goyal L, Davis M, Kaymakcalan MD and Williams JS: Clinical risk factors for the development of hypertension in patients treated with inhibitors of the VEGF signaling pathway. Cancer 121: 311-319, 2015.

19. Ciamporcero E, Miles KM, Adelaiye R, Ramakrishnan S, Shen L, Ku S, Pizzimenti S, Sennino B, Barrera G and Pili R: Combination strategy targeting VEGF and HGF/c-met in human renal cell carcinoma models. Mol Cancer Ther 14: 101-110, 2015.

20. Jannuzzi AT, Özhan G, Yanar HT and Alpertunga B: VEGF gene polymorphisms and susceptibility to colorectal cancer. Genet Test Mol Biomarkers 19: 133-137, 2015.

This work is licensed under a Creative Commons Attribution-NonCommercial-NoDerivatives 4.0 International (CC BY-NC-ND 4.0) License. 